\title{
HUBUNGAN PERAN TENAGA KESEHATAN, DUKUNGAN SUAMI DAN MEDIA INFORMASI DENGAN PEMERIKSAN INSPEKSI VISUAL ASAM ASETAT (IVA) DI WILAYAH KERJA PUSKESMAS TALANG JAYA TAHUN 2019
}

\author{
Riztia Rahmadini ${ }^{1}$, Minarti ${ }^{2}$ \\ Program Studi DIV Kebidanan Universitas Kader Bangsa Palembang. \\ Jalan H.M.Ryacudu No 887 Ulu Palembang \\ Email : riztiarahmadini1212@gmail.com
}

\begin{abstract}
Abstrak
Penyakit kanker merupakan salah satu penyebab kematian dengan jumlah terbanyak di dunia. Berdasarkan estimasi data World Health Organization (WHO) Tahun 2013 terdapat hanya 5\% wanita di negara berkembang yang hanya melakukan deteksi dini. Tujuan penelitian ini adalah untuk mengetahui hubungan peran tenaga kesehatan, dukungan suami dan media informasi dengan pemeriksaan inspeksi visual asam asetat (IVA) di Wilayah Kerja Puskesmas Talang Jaya Kabupaten Banyuasin tahun 2019. Jenis penelitian ini menggunakan metode survey analitik dengan pendekatan Cross Sectional. Dengan jumlah sampel berjumlah 77 responden dan diperoleh hasil uji statistik chi square pada batas $\alpha=0,05$ dan $d f=1$. Perant tenaga kesehatan $p$ value $=0,000$, Dukungan Suami $p$ value $=0,007$ dan Akses informasi $p$ value $=0,002 \leq \alpha=0,05$ hal ini menunjukkan bahwa ada hubungan yang bermakna antara peran petugas kesehatan, dukungan suami dan akses informasi. dengan pemeriksaan inspeksi visual asam asetat (IVA). Kesimpulan dalam penelitian ini ada hubungan peran tenaga kesehatan, dukungan suami dan media informasi dengan pemeriksaan inspeksi visual asam asetat (IVA) di Wilayah Kerja Puskesmas Talang Jaya. Saran diharapkan agar penelitian ini dapat dijadikan bahan pertimbangan dalam pengambilan keputusan, dapat meningkatkan mutu pelayanan dan penyuluhan khususnya tentang pemeriksaan IVA sehingga penderita kanker servik dapat diatasi sedini mungkin.
\end{abstract}

Kata Kunci: Pemeriksaan IVA, Peran Petugas Kesehatan, Dukungan Suami dan Akses Informasi

\begin{abstract}
Cancer is one of the leading causes of death in the world. Based on data from the World Health Organization (WHO) in 2013 there were only 5\% of women in developing countries who only did early detection. The purpose of this study was to find out the relationship between the role of health personnel, husband support and information media by visual inspection of acetic acid (Iiva) in the Talang Jaya Community Health Center Working Area in Banyuasin District in 2019. This type of research uses analytical survey method with Cross Sectional approach. With a total sample of 77 respondents and obtained the results of chi square statistical test on the boundary $\alpha=0.05$ and $d f=1$. Perant health workers $p$ value $=0,000$, Husband Support $p$ value $=0.007$ and Access information $p$ value $=0.002 \leq \alpha$ $=0,05$ this shows that there is a meaningful relationship between the role of health workers, husband support and access to information. with a visual inspection examination of acetic acid (iva). The conclusion in this study is that there is a relationship between the role of health workers, husband support and information media with visual inspection of acetic acid (Iiva) in the Talang Jaya Health Center Working Area. Suggestions for Research Results It is hoped that this research can be used as a consideration in decision making, can improve the quality of services and counseling especially about IVA examination so that patients with cervical cancer can be treated as early as possible.
\end{abstract}

Keywords: IVA Examination, Role of Health Officers, Husband Support and Information Access 


\section{PENDAHULUAN}

Penyakit kanker merupakan salah satu penyebab kematian dengan jumlah terbanyak di dunia. Berdasarkan data Internasional Agency For Research on Cancer (IARC) didapatkan data pada tahun 2014 bahwa setiap tahunnya untuk angka kanker meningkat sekitar 19\% dengan tingkat kematian per 100.000 orang pertahun.

Salah satu jenis kanker yang sering ditemukan pada wanita adalah kanker serviks. Kanker serviks menduduki urutan tertinggi di negara berkembang dan berada pada urutan ke 10 di negara maju atau urutan ke 5 secara global. Dengan jumlah kasus 550,000 diseluruh dunia (IARC, 2014). Kanker serviks merupakan pembunuh nomor dua pada wanita setelah kanker payudara (Kemenkes RI, 2015).

Salah satu alasan semakin berkembangnya kanker serviks tersebut disebabkan oleh rendahnya cakupan deteksi dini kanker serviks. Berdasarkan estimasi data World Health Organization (WHO) Tahun 2013 terdapat hanya 5\% wanita di negara berkembang yang hanya melakukan deteksi dini.

WHO mengatakan terdapat 490.000 wanita didunia yang terkena kanker serviks pada tiap tahunnya disebabkan karena keterlambatan dalam deteksi dini. Pada umumnya wanita datang ke pelayanan kesehatan ketika akan memeriksa kondisinya dalam kedaan kanker sudah menyebar ke organ lain sehingga menimbulkan pengobatan yang sulit (Astrid, 2015).

Di Indonesia untuk kasus kanker berjumlah yaitu 1.027.763 kasus (Riskesdas, 2013). Kanker serviks menduduki urutan kedua dari 10 kanker dengan jumlah kasus kanker serviks sebanyak 522.354 kasus (Kemenkes RI, 2015).

Kanker serviks dapat dicegah dengan beberapa metode skrining yang dilakukan di rumah sakit maupun puskesmas.
Metode-metode yang digunakan antara lain test Pap Smear (mengambil lender serviks untuk diperiksa di laboratorium), IVA (Inspeksi Visual Asam Asetat), Kolposkopi (pemeriksaan dengan menggunakan teropong), dan biopsy (Astrid, 2015).

Beberapa faktor yang menjadi penghambat dalam program pemerintah yang telah ditetapkan antara lain wilayah yang sangat luas, kurangnya SDM sebagai pelaku skrining, kurangnya tenaga ahli patologi anatomi, dan masih rendahnya kesadaran masyarakat untuk melakukan skrining. Tidak semua skrining sulit untuk dilakukan, seperti pemeriksaan IVA. Ada beberapa keuntungan IVA antara lain, mudah dan praktis serta dapat dilakukan oleh seluruh tenaga kesehatan dengan alatalat yang sederhana sehingga sesuai untuk pusat pelayanan sederhana (Afiyanti, 2017).

Faktor-faktor yang mempengaruhi pemeriksaan IVA adalah peran tenaga kesehatan, dukungan suami, media informasi, umur, pendidikan, status pernikahan, paritas, pengetahuan, dan sikap (Lailawati, 2016).

Berdasarkan masalah di atas, peneliti tertarik untuk meneliti Hubungan Peran Tenaga Kesehatan, Dukungan Suami dan Media Informasi dengan Pemeriksan Inspeksi Visual Asam Asetat (IVA) di Wilayah Kerja Puskesmas Talang Jaya Kabupaten Banyuasin tahun 2019.

\section{METODE PENELITIAN}

Penelitian ini menggunakan Survei Analitik dengan metode pendekatan cross sectionalstudi analitik untuk mengetahui hubungan antara variabel independen dan variabel dependen. Maka pengukuran dilakukan secara bersama-sama pada saat penelitian dengan menggunakan kuesioner (Notoatmodjo, 2011).

\section{Jenis Penelitian \\ Penelitian ini menggunakan pendekatan kuantitatif.}




\section{Waktu dan Tempat Penelitian}

Penelitian ini dilaksanakan di Wilayah Kerja Puskesmas Talang Jaya Kabupaten Banyuasin pada bulan Januari-Juni 2019.

\section{Target/Subjek Penelitian}

Populasi dalam penelitian ini adalah seluruh wanita usia subur yang berada di Wilayah Kerja Puskesmas Talang Jaya Kabupaten Banyuasin dalam penelitian ini jumlah sampel yang digunakanberjumalah 77 WUS yang diperoleh dengan teknik acidental sampling.

\section{Prosedur}

Pengummpulan data merupakan kegiatan penelitian untuk mengumpulkan data perlu dilihat alat ukur pengumpulan data agar dapat memperkuat hasil penelitian alat ukur penelitian yang digunakanadalah:

1. Angket/Koesioner : alat ukur koesioner dengan beberapa pertanyaan

2. Observasi : pengumpulan data dengan melakukan pengamatan secara langsung kepada responden untuk mencari perubahan atau hal-hal yang akan diteliti

3. Wawancara: Metode pengumpulan data dengan cara mewawancarai langsung responden yang diteliti

\section{Data, Intrumen, dan Teknik Pengumpulan Data}

Data dalam penelitian ini berupa data primer. Data primer adalah data diperoleh dari wawancara langsung kepada responden menggunakan kuesioner.

\section{Teknik Analisis Data}

Menggunakan analisa univariat dananalisa bivariat. analisis univariat adalah analisis yang dilakukan terhadap tiap variabel dari hasil penelitian. Dan Analisa bivariat merupakan analisis yang dilakukan terhadap dua variabel yang diduga berhubungan atau berkolerasi (Notoatmodjo, 2011). Analisis ini dilakukan untuk mengetahui hubungan antara variabel independen (peran tenaga kesehatan, dukungan suami, media informasi) dan variabel dependen (pemeriksaan IVA) di Wilayah Kerja Puskesmas Talang Jaya Kabupaten Banyuasin yang dianalisis dengan uji statistik Chi-Square dan menggunakan komputerisasi dengan tingkat kemaknaan $\alpha=0,05$.

\section{HASIL PENELITIAN}

\section{Analisis Univariat}

Analisis dilakukan pada 77 responden yang bertujuan untuk mengetahui distribusi frekuensi dan persentase dari tiap variabel yaitu variabel dependen (Pemeriksaan IVA) dan variabel independen (Peran Petugas Kesehatan, Motivasi dan Akses Informasi). Data disajikan dalam bentuk tabel dan teks, dapat dilihat Tabel 1. berikut.

Tabel 1. Distribusi frekuensi variabel independen dan dependen

\begin{tabular}{llcc}
\hline No & \multicolumn{1}{c}{ Variabel } & Jumlah & $\begin{array}{c}\text { Persenta } \\
\text { se }\end{array}$ \\
\hline 1 & Pemeriksaan IVA & & \\
& Ya & 46 & 59,7 \\
& Tidak & 31 & 40,3 \\
\hline 2 & Peran Petugas & & \\
& Kesehatan & 44 & 57,1 \\
& Ya & 33 & 42,9 \\
& Tidak & & \\
\hline 3 & Dukungan Suami & 33 & 42,9 \\
& Mendukung & 44 & 57,1 \\
& Tidak Mendukung & & \\
\hline 4 & Akses Informasi & 38 & 49,4 \\
& Ya & 39 & 50,6 \\
& Tidak & \\
\hline
\end{tabular}

\section{Analisis Bivariat}

Analisis dilakukan untuk mengetahui apakah ada hubungan antara variabel independen (Peran petugas kesehatan, dukungan suami dan akses informasi) dan variabel dependen 
(Pemeriksaan IVA) dengan uji statistik Chi-Square ( $\left.\mathrm{X}^{2}\right)$ dengan komputerisasi, dengan tingkat kemaknaan $\alpha=0,05$ hasil keputusan diperoleh dengan perbandingan $\rho$ value dengan $\alpha=0,05$. bila $\rho$ value $\leq$ 0,05 bearti ada hubungan yang bermakna dan bila $\rho$ value $\geq 0,05$ bearti tidak ada hubungan antara variabel independen dan variabel dependen ( Notoadmojo, 2005 ).

Tabel 2. Hubungan peran tenaga kesehatan dengan pemeriksaan IVA

\begin{tabular}{|c|c|c|c|c|c|c|c|c|c|}
\hline \multirow{3}{*}{$\begin{array}{l}\mathrm{N} \\
\mathrm{o}\end{array}$} & \multirow{3}{*}{$\begin{array}{c}\text { Peran } \\
\text { Petugas } \\
\text { Kesehat } \\
\text { an }\end{array}$} & \multicolumn{4}{|c|}{ Pemeriksaan IVA } & \multicolumn{2}{|c|}{ Jumlah } & \multirow{2}{*}{$\begin{array}{c}\rho \\
\text { value }\end{array}$} & \multirow[t]{2}{*}{$O R$} \\
\hline & & \multicolumn{2}{|c|}{$\mathrm{Ya}$} & \multicolumn{2}{|c|}{ Tidak } & & & & \\
\hline & & $\mathrm{n}$ & $\%$ & $\mathrm{n}$ & $\%$ & $\mathrm{~N}$ & $\%$ & $\begin{array}{c}\rho \\
\text { value }\end{array}$ & 4,6 \\
\hline 1 & $\mathrm{Ya}$ & $\begin{array}{l}3 \\
3\end{array}$ & $\begin{array}{c}75, \\
0\end{array}$ & $\begin{array}{l}1 \\
1\end{array}$ & $\begin{array}{r}25 \\
, 0\end{array}$ & 44 & $\begin{array}{c}10 \\
0\end{array}$ & $\begin{array}{c}0,00 \\
0\end{array}$ & \\
\hline 2 & Tidak & 3 & $\begin{array}{c}39, \\
4\end{array}$ & 0 & $\begin{array}{r}60 \\
6\end{array}$ & 33 & $\begin{array}{c}10 \\
0\end{array}$ & & \\
\hline & Total & $\begin{array}{l}4 \\
6\end{array}$ & $\begin{array}{c}59, \\
7 \\
\end{array}$ & $\begin{array}{l}3 \\
1\end{array}$ & $\begin{array}{l}40 \\
, 3 \\
\end{array}$ & 77 & $\begin{array}{c}10 \\
0\end{array}$ & & \\
\hline
\end{tabular}

Berdasarkan tabel 2 diatas, terlihat bahwa dari 44 responden yang memanfaatkan peran petugas kesehatan dan melakukan pemeriksaan IVA berjumlah 33 responden $(75,0 \%)$ dan yang tidak berjumlah 11 responden $(25,0 \%)$.

Setelah dilakukan secara uji statistik dengan " Chi Square diperoleh $\rho$ value = 0,000. Dengan demikian hipotesis yang menyatakan ada hubungan yang bermakna antara peran petugas kesehatan dengan pemeriksaan IVA di Wilayah Kerja Puskesmas Talang Jaya Kabupaten Banyuasin terbukti secara statistik.

Nilai odds ratio didapat 4,6 artinya petugas kesehatan yang berperan akan berpeluang 4,6 kali lebih besar melakukan pemeriksaan IVA dibandingkan dengan petugas kesehatan yang tidak berperan.

\section{Tabel 3. Hubungan dukungan suami} dengan pemeriksaan IVA

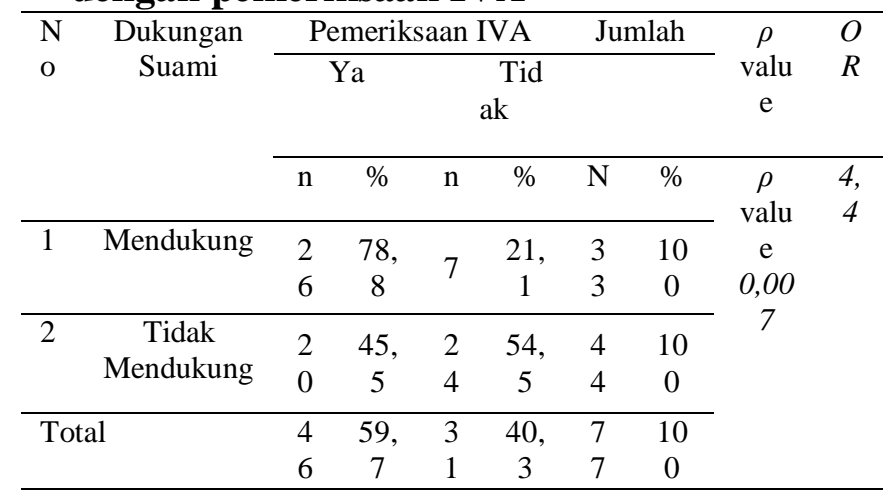

Berdasarkan tabel 3 diatas, terlihat bahwa dari 33 responden yang suaminya mendukung dan melakukan pemeriksaan IVA berjumlah 26 responden $(78,8 \%)$ dan yang tidak berjumlah 7 responden $(21,1)$.

Setelah dilakukan secara uji statistik dengan " Chi Square diperoleh $\rho$ value $=$ 0,007. Dengan demikian hipotesis yang menyatakan ada hubungan yang bermakna antara dukungan suami dengan pemeriksaan IVA.

Nilai odds ratio didapat 4,4 artinya dukungan suami yang mendukung akan berpeluang 4,4 kali lebih besar melakukan pemeriksaan IVA dibandingkan dengan dukungan suami yang tidak mendukung.

Tabel 4. Hubungan Akses informasi dengan pemeriksaan IVA

\begin{tabular}{|c|c|c|c|c|c|c|c|c|c|}
\hline \multirow{3}{*}{$\begin{array}{l}\mathrm{N} \\
\mathrm{O}\end{array}$} & \multirow{3}{*}{$\begin{array}{c}\text { Akses } \\
\text { Informas } \\
\text { i }\end{array}$} & \multicolumn{4}{|c|}{ Pemeriksaan IVA } & \multicolumn{2}{|c|}{ Jumlah } & \multirow{2}{*}{$\begin{array}{c}\rho \\
\text { valu } \\
\mathrm{e} \\
\end{array}$} & \multirow[t]{2}{*}{$O R$} \\
\hline & & \multicolumn{2}{|c|}{$\mathrm{Ya}$} & \multicolumn{2}{|c|}{ Tidak } & & & & \\
\hline & & $\mathrm{n}$ & $\%$ & $\mathrm{n}$ & $\%$ & $\mathrm{~N}$ & $\%$ & \multirow{7}{*}{$\begin{array}{c}\rho \\
\text { valu } \\
\mathrm{e} \\
0,00 \\
2\end{array}$} & \multirow{7}{*}{5,3} \\
\hline \multirow[t]{2}{*}{1} & $\mathrm{Ya}$ & 3 & 78, & & 21 , & 3 & 10 & & \\
\hline & & 0 & 9 & $\gamma$ & 1 & 8 & 0 & & \\
\hline \multirow[t]{2}{*}{2} & Tidak & 1 & 41 , & 2 & 59 , & 3 & 10 & & \\
\hline & & 6 & 0 & 3 & 0 & 9 & 0 & & \\
\hline \multirow{2}{*}{\multicolumn{2}{|c|}{ Total }} & 4 & 59 , & 3 & 40. & 7 & 10 & & \\
\hline & & 6 & 7 & 1 & 3 & 7 & 0 & & \\
\hline
\end{tabular}

Berdasarkan tabel 4 diatas, terlihat bahwa dari 38 responden yang memiliki akses informasi dan melakukan pemeriksaan IVA berjumlah 30 responden $(78,9 \%)$ dan yang tidak berjumlah 8 responden $(21,1 \%)$.

Setelah dilakukan secara uji statistik dengan " Chi Square diperoleh $\rho$ value $=$ 
0,002. Dengan demikian hipotesis yang menyatakan ada hubungan yang bermakna antara akses informasi dengan pemeriksaan IVA di Wilayah Kerja Puskesmas Talang Jaya Kabupaten Banyuasin terbukti secara statistik.

Nilai odds ratio didapat 5,3 artinya responden yang memiliki akses impormasi akan berpeluang 5,3 kali lebih besar melakukan pemeriksaan IVA dibandingkan dengan responden yang tidak memiliki akses impormasi.

\section{PEMBAHASAN}

\section{Hubungan Peran Tenaga Kesehatan Dengan Pemeriksaan Informasi di Wilayah Kerja Puskesmas Talang Jaya Kabupaten Banyuasin}

Berdasarkan analisis bivariat terlihat bahwa dari 44 responden yang memanfaatkan peran petugas kesehatan dan melakukan pemeriksaan IVA berjumlah 33 responden $(75,0 \%)$ dan yang tidak berjumlah 11 responden $(25,0 \%)$. Setelah dilakukan secara uji statistik dengan " Chi Square diperoleh $\rho$ value $=$ 0,000 . Dengan demikian hipotesis yang menyatakan ada hubungan yang bermakna antara peran petugas kesehatan dengan pemeriksaan IVA di Wilayah Kerja Puskesmas Talang Jaya Kabupaten Banyuasin terbukti secara statistik.

Nilai odds ratio didapat 4,6 artinya petugas kesehatan yang berperan akan berpeluang 4,6 kali lebih besar melakukan pemeriksaan IVA dibandingkan dengan petugas kesehatan yang tidak berpera.

Dukungan tenaga kesehatan merupakan bantuan dari orang lain khususnya tenaga kesehatan terhadap seseorang terkait kondisi kesehatannya (Yusuf LN dalam Lailawati, 2016). Dukungan dari profesional kesehatan merupakan faktor yang dapat mempengaruhi perilaku kepatuhan individu.
Dukungan tersebut berguna bagi individu dalam berperilaku sehat, profesional kesehatan juga dapat mempengaruhi perilaku individu dengan cara menyampaikan antusias terhadap tindakan tertentu dan memberikan penghargaan yang positif bagi individu yang mampu berpartisipasi dengan program kesehatan (Lailawati, 2016).

Dukungan petugas kesehatan yang baik ini dapat diperoleh dari salah satu faktor yang dapat dilihat dari faktor pemberi dukungan, dukungan sosial tersebut akan lebih efektif jika bersumber dari orang-orang yang mempunyai arti dalam hidup seseorang (Lailawati, 2016).

Mendapatkan dukungan dari petugas kesehatan karena petugas kesehatan memiliki peranan dalam meningkatkan kualitas pelayanan kesehatan yang maksimal kepada masyarakat agar masyarakat mampu untuk meningkatkan kesadaran, kemauan, dan kemampuan hidup sehat sehingga akan terwujud derajat kesehatan yang setinggitingginya (UU Republik Indonesia, 2014).

Masyarakat yang sudah mendapatkan dukungan tinggi dari petugas kesehatan juga masih banyak yang tidak melakukan kunjungan skrining kanker serviks, hal ini disebabkan karena masih ada banyak faktor lain yang mempengaruhi PUS melakukan kunjungan pemeriksaan seperti faktor pengetahuan, sikap, pendidikan, budaya, keterjangkauan jarak, keterjangkauan biaya, maupun dukungan dari keluarga (Lailawati, 2016).

Sedangkan Masyarakat yang masih mendapatkan dukungan rendah dapat disebabkan karena ada faktor-faktor yang menghambat dari pemberian dukungan seperti penarikan diri dari orang lain, tidak mau menerima bantuan dari orang lain, maupun melawan orang lain seperti sikap curiga, tidak sensitif, maupun tidak ada timbal balik (Apollo \& Cahyadi 2012 dalam Lailawati, 2016). 


\section{Hubungan dukungan suami Dengkan Pemeriksaan IVA di Wilayah Kerja Puskesmas Talang Jaya Kabupaten Banyuasin}

Berdasarkan analisis bivariat terlihat bahwa bahwa dari 33 responden yang suaminya mendukung dan melakukan pemeriksaan IVA berjumlah 26 responden $(78,8 \%)$ dan yang tidak berjumlah 7 responden $(21,1)$.

Setelah dilakukan secara uji statistik dengan " Chi Square diperoleh $\rho$ value $=$ 0,007 . Dengan demikian hipotesis yang menyatakan ada hubungan yang bermakna antara dukungan suami dengan pemeriksaan IVA.

Nilai odds ratio didapat 4,4 artinya dukungan suami yang mendukung akan berpeluang 4,4 kali lebih besar melakukan pemeriksaan IVA dibandingkan dengan dukungan suami yang tidak mendukung.

Dukungan suami merupakan suatu dukungan yang terdiri dari nasihat verbal dan non verbal bantuan nyata dan tindakan yang diberikan oleh keakraban atau didapat karena kehadiran mereka dan mempunyai manfaat emosional atau efek perilaku bagi pihak penerima. Dukungan suami menjadi faktor penetu karena akan memberikan motivasi untuk melakukang deteksi dini kangker servik (wahyuni, 2013)

Hasil penelitian dukungan suami mendorong keikut sertaan pemeriksaan pap smear pasangan usia subur (PUS) diperumahan Pucang Gading Semarang menyatakan sebanyak 15 responden (20\%) melakukan pap smear. Dukungan suami dan pengetahuan memiliki hubungan yang siknifikan terhadap keikut sertaan pap smear ( $\mathrm{p}$ Value <0,05).

Hasil penelitian ini juga sejalan dengan penelitian kurniawati 2010, menyatakan bahwa ada hubungan yang signifikan antara dukungan suami dengan WUS yang melakukan pemeriksaan IVA didapatkan hasil bahwa dukungan suami dalam katagori baik yaitu sejumlah 79 orang $(84,0 \%)$ sedangkan katagori kurang berjumlah 15 orang $(16,0 \%)$.

\section{Hubungan Akses Informasi Dengan Pemeriksaan IVA di Wilayah Kerja Puskesmas Talang Jaya Kabupaten Banyuasin}

Berdasarkan hasil analisis bivariat terlihat bahwa dari 38 responden yang memiliki akses informasi dan melakukan pemeriksaan IVA berjumlah 30 responden $(78,9 \%)$ dan yang tidak berjumlah 8 responden $(21,1 \%)$.

Setelah dilakukan secara uji statistik dengan " Chi Square diperoleh $\rho$ value $=0,002$. Dengan demikian hipotesis yang menyatakan ada hubungan yang bermakna antara akses informasi dengan pemeriksaan IVA di Puskesmas Wilayah Kerja Puskesmas Talang Jaya Kabupaten Banyuasin terbukti secara statistik.

Nilai odds ratio didapat 5,3 artinya responden yang memiliki akses impormasi akan berpeluang 5,3 kali lebih besar melakukan pemeriksaan IVA dibandingkan dengan responden yang tidak memiliki akses impormasi.

Menurut Notoatmodjo (2013), akses informasi pada hakekatnya mendukung atau memungkinkan terwujudnya pelaksanaan deteksi dini kanker serviks, faktor ini disebut faktor pendukung. Akses informasi mengenai kesehatan reproduksi terutama kesehatan reproduksi wanita dapat diperoleh dari majalah, leaflet, poster, televisi, buku kesehatan dan lainnya.

Dari hasil penelitan, peneliti berasumsi bahwa pada WUS yang banyak tidak melakukan kunjungan IVA dipengaruhi oleh tidak adanya akses informasi yang digunakan maupun didapatkan, disebabkan oleh rasa acuh 
tak acuh pada kesehatan, menganggap jika Belum ada keluhan maka wanita tidak melakukan pemeriksaan IVA dan disebabkan kurangnya penyuluhanpenyuluhan tentang metode IVA yang dapat dilakukan dari pihak Puskesmas, kader kesehatan maupun kerjasama antara kampus dengan puskesmas dalam menjalankan kegiatan penyuluhan.

Hal ini sesuai teori Puspita (2015), informasi kesehatan tentang kanker serviks sangat penting didapat oleh WUS terutama dalam pencegahan melalui deteksi dini metode IVA, informasi yang tidak diperoleh oleh WUS merupakan salah satu masalah dan penyebab wanita terus diburu oleh penyakit berbahaya ini.

Informasi dapat di akses melalui media, menurut (Kholid, 2017) media adalah alat peraga dalam promosi kesehatan dapat diartikan sebagai alat bantu untuk promosi kesehatan yang dapat dilihat, di dengar, diraba, dirasa atau dicium, untuk memperlancar komunikasi dan penyebar-luasan informasi.

\section{SIMPULAN}

Ada hubungan peran tenaga kesehatan, dukungan suami dan akses informasi secara simultan terhadap pemeriksaan Inspeksi Visual Asam Asetat (IVA) di Wilayah Kerja Puskesmas Talang Jaya Kabupaten Banyuasin Tahun 2019.

\section{SARAN}

Diharapkan agar penelitian ini dapat dijadikan bahan pertimbangan dalam pengambilan keputusan, dapat meningkatkan mutu pelayanan dan penyuluhan khususnya tentang pemeriksaan IVA sehingga penderita kanker servik dapat di diatasi sedini mugkin.

\section{UCAPAN TERIMA KASIH}

Penulis mengucapkan banyak terima kasih kepada kedua orang tua saya yang telah memberi dukungan materil maupun suport yang tak terhingga terhadap penelitian ini. Dan tak lupa pula saya ucapkan banyak terima kasih kepada dosen pembimbing saya ibu Eka Afrika, SST, M.Kes, dan Ibu Minarti, SST, M.Kes yang telah banyak membantu saya dalam penelitian ini.

\section{DAFTAR PUSTAKA}

BKKBN. 2008. Peningkatan partisipasi suami dalam kesehatan reproduksi. Jakarta: BKKBN

Delia, Wijaya. 2010. Pembunuh Ganas Itu Bernama Kanker Serviks. Yogyakarta : Sinar Kejora.

Departemen Kesehatan RI. Skrining Kanker Leher Rahim Dengan Metode Inspeksi Visu

\section{Depkes RI. 2009.Pencegahan Kanker}

Leher Rahim. From:

http//www.Depkes.go.id. di akses tgl 28 april 2019

Kementerian Kesehatan RI. Situasi Penyakit Kanker. Pusat Data dan Informasi, Jakarta. 2015. 8. Kementerian Kesehatan RI. 2015, Infodatin Stop Kanker. Pusat Data Kesehatan, Jakarta. 9. Gan DE,\& Dahl

Kemenkes. Rencana Strategis kementerian kesehatan tahun 2015-2019. Jakarta: Kementerian RI: 2015

Kholid, Ahmad, 2012. Promosi Kesehatan dengan pendekatan teori prilaku, media, dan aplikasinya. Perpustakaan Nasional: Katalog Dalam Terbitan (KDT). Jakarata : Rajawali Pers

Linadi, K.S. Dukungan Suami Mendorong Keikutsertaan Pap Smear Pasangan Usia Subur (Pus) Di Perumahan Pucang Gading Semarang. Jurnal Kesehatan 
Reproduksi, vol. 4, no. 2., pp 61-71. 2013.

Notoatmodjo,S. 2010. Metodologi

Penelitian Kesehatan. Jakarta: Rineka

Cipta

.2005. Ilmu kesehatan

masyarakat. Jakarta: Rineka Cipta.

Saam, Zulfan dan Sri wahyuni. 2012.

Psikologi keperawatan. Jakarta :

Raja Grafindo Persada. 